\title{
Assessment of the plume theory predictions of crown scorch or crown fire initiation using transport models
}

\author{
V. Konovalov ${ }^{1,2}$, J.-L. Dupuy ${ }^{1}$, F. Pimont ${ }^{1}$, D. Morvan ${ }^{3}$ \\ \& R. R. Linn $^{4}$ \\ ${ }^{I}$ I.N.R.A. Ecologie des Forêts Méditerranéennes (UR 629) Site Agroparc, \\ Domaine de Saint Paul, F-84914 Avignon. France \\ ${ }^{2} I C M M$, Ural Branch of RAS, Perm, Russia \\ ${ }^{3}$ UNIMECA,Université de la Méditerranée, Marseille, France \\ ${ }^{4}$ EES2, Los Alamos National Laboratory, Los Alamos, USA
}

\begin{abstract}
The aim of our work is to numerically study crown scorch and crown fire ignition as the effects of a fire line spreading through surface fuel under a tree canopy. The objective was to assess the usual assumptions made when one uses the Van Wagner criteria, based on plume theory, to estimate crown scorch or crown fire ignition. The Van Wagner criteria are indeed simple predictive models for crown scorch height or crown fire initiation occurrence. For this purpose the FIRESTAR 2D and FIRETEC wildfire simulators are used. We simulated the fire line by a heat source at ground level and mainly investigated the temperature field. As a first step, we tested the sensitivity of the simulations to different simulation parameters of the wildfire models. As a second step, we ran computations of thermal plumes with no-wind and with no-canopy, for the first comparison to the plume theory. The influence of crown existence on the temperature field above the heat source, as well as on crown scorch and fire ignition conditions, was then investigated. As a third step, the effect of a wind to the plume was shown for the no-canopy and canopy cases.
\end{abstract}

Keywords: crown scorch and crown fire ignition, plume theory, van Wagner criteria, FIRESTAR 2D and FIRETEC wildfire simulators. 


\section{Introduction}

The Van Wagner criteria are simple predictive models for crown scorch height or crown fire initiation occurrence, based on plume theory. These criteria are widely used by forest engineers to assess the risk of crown scorch or of crown fire ignition in the prescribed fire operations.

Following some preliminary work [1, 2], Van Wagner derived from the plume theory a formula relating the crown scorch height with the linear fire front intensity [3]:

$$
h_{s}=11.61 \frac{I^{2 / 3}}{60-t_{a}}
$$

where $h_{s}(\mathrm{~m})$ is the crown scorch height, $I(\mathrm{~kW} / \mathrm{m})$ is the linear fire front intensity, $t_{a}\left({ }^{\circ} \mathrm{C}\right)$ is the ambient temperature. The numerical constant was derived from the experimental data. Crown scorch was assumed to appear at the usual value of $60^{\circ} \mathrm{C}$. This temperature threshold is actually well adapted for the prediction of tree foliage necrosis, even if higher thresholds should be used for vegetative buds [4]. Vegetative buds have indeed a higher response time to a heat flux than needles, due to their lower surface-to-volume ratio. Here, we will consider that the fuel elements are in thermal equilibrium with the gaseous phase, which thus is well supported for foliage (except during water evaporation process), but not for buds. A basic assumption of plume theory is to consider points far enough from the heat source. It also means that the main mechanism of heat transfer is convection, since heat-conduction or radiation should only be significant close to the source. Van Wagner criterion also assumes that the plume structure is not significantly affected by the presence of a canopy. In [3], Van Wagner investigated the effect of a weak wind on crown scorch. By a weak wind, we mean that plume structure is not destroyed with wind, but just inclined [2]. A simple correction gives the scorch height including the effect of wind:

$$
h_{s}=\frac{3.94 I^{7 / 6}}{\left(0.107 I+U^{3}\right)\left(60-t_{a}\right)},
$$

where $U(\mathrm{~m} / \mathrm{s})$ is the wind velocity.

In the present study, we intended to assess the main assumptions made in the previous theory. To investigate numerically crown scorch and crown fire ignition as the effects of a fire line spreading through surface fuel under a tree canopy, we used two different physically-based fire models: FIRESTAR 2D [5] and FIRETEC [6]. In both models, a heat source was implemented, as a rectangle area located in the middle of the domain and put at ground level. The heat source represents a steady fire line of given intensity (power in $\mathrm{kW} / \mathrm{m}$ ). The influence of a canopy and an ambient wind were also included. The sensitivity of the simulations to different simulation parameters of the wildfire simulators was tested. 


\section{Wildfire simulator parameters}

\subsection{FIRETEC simulations}

FIRETEC is a 3D coupled fire-atmosphere model, developed at Los Alamos National Laboratory (New Mexico, USA). It is based on conservation of mass, momentum, species and energy in compressible-gas formulation. Turbulence modelling within FIRETEC is close to the large-eddy simulation approach. The $3 \mathrm{D}$-geometry of the numerical simulation is very interesting in terms of fire behaviour analysis, but requires a significant computational cost. For that reason, the spatial resolution remains limited to the order of $1 \mathrm{~m}$ at ground level (in practice, $2 \mathrm{~m}$ size cells are usually selected). The combustion model treats vegetation pyrolysis and combustion as a single process and is based on a Probability Density Function for temperature. In the present study, the heater was defined as a line of cells in the middle of the domain at ground level.

We tested the effect of the spatial resolution on simulation outputs. For that purpose, we considered numerical domains of a given size $(160 \mathrm{~m}$ in length, $20 \mathrm{~m}$ in width and $615 \mathrm{~m}$ in height) with cyclic boundary conditions on the lateral domain sides, but with different mesh size along the $x, y$ and $z$ axis. Mesh resolutions were characterized by their cell size at ground level: $1 \mathrm{~m} \times 1 \mathrm{~m} \times 1 \mathrm{~m}$, $1 \mathrm{~m} \times 1 \mathrm{~m} \times 2 \mathrm{~m}, 1 \mathrm{~m} \times 2 \mathrm{~m} \times 1 \mathrm{~m}, 2 \mathrm{~m} \times 2 \mathrm{~m} \times 1 \mathrm{~m}, 2 \mathrm{~m} \times 2 \mathrm{~m} \times 2 \mathrm{~m}$, and $4 \mathrm{~m} \times 4 \mathrm{~m} \times$ $4 \mathrm{~m}$. It should be notice that cell heights increased along the vertical axis.

Fig. 1 shows the effect of the mesh resolution to the temperature field output for the case of the heater power $250 \mathrm{~kW} / \mathrm{m}$.

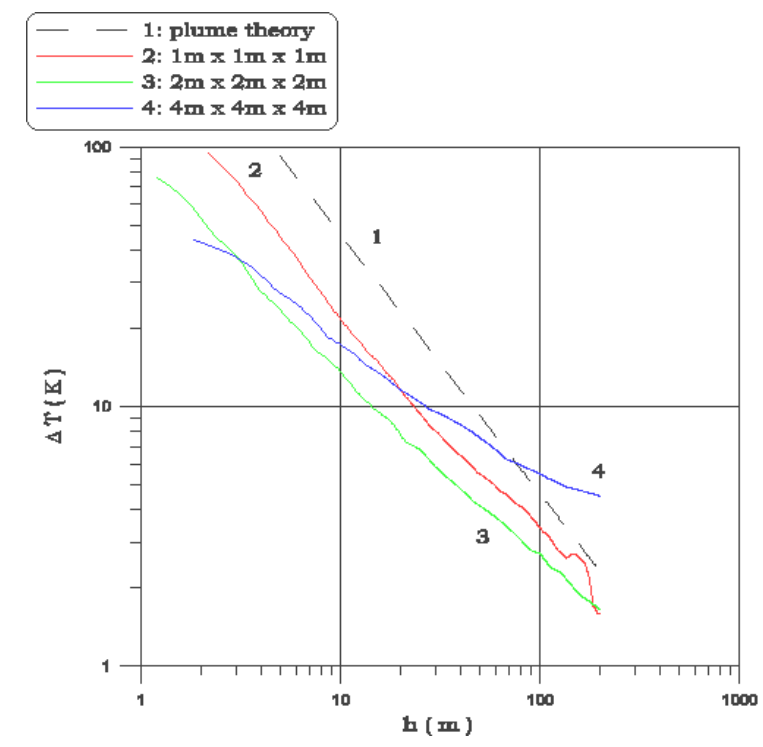

Figure 1: Vertical profiles of the temperature rise, as predicted by the FIRETEC model. 
The curves obtained with logarithmic axis for all the different meshes were almost linear. In addition, their slopes are generally close to -1 , as it is predicted by plume theory (Fig. 1). However, the slopes depended on mesh resolution and some discrepancies to the -1 slope appeared at the lowest resolution (curve 4 on Fig 1).

The -1 slope in log scale is a requirement of plume theory, obtained by dimensional analysis. But it must be specified that plume theory predicts the maximum temperature on the plume axis (point temperature), since FIRETEC predicts an average temperature over the cell volume. FIRETEC predictions should match plume theory when temperature gradients are small enough. The conclusion of these preliminary results was the following: in order to get the plume temperatures as predicted by plume theory and other field output of the plume above the heater, we need to use rather fine mesh, especially for the vertical direction. The standard mesh resolution $2 \mathrm{~m} \times 2 \mathrm{~m} \times 2 \mathrm{~m}$ doesn't seem enough.

\subsection{FIRESTAR 2D simulations}

FIRESTAR is a 2D-geometry wildfire behaviour simulator, developed at Mediterranean University (Marseille, France). The combustion processes are described with more details than in FIRETEC and the spatial resolution in higher, but the 2D assumption raises questions. The turbulence model is based on a k- $\varepsilon$ approach. The mesh size in FIRESTAR can be refined in the area of interest, namely the heat source and the plume here.

In the study, the heater was also defined as a set of cells in the middle of the domain at ground level. The mesh size was $0.2 \mathrm{~m} \times 0.1 \mathrm{~m}$ at burner location. The numerical domain was $100 \mathrm{~m}$ long and $50 \mathrm{~m}$ high. We tested three different modes for the simulation of the heat source. In the two first ways, we injected a mass of $\mathrm{CO}$ in the heat source area that reacted with oxygen to release heat. Two models of combustion rate were tested for the simulated burner: the first one was based on the Eddy Dissipation Concept; the second one assumed that either CO or oxygen was fully consumed by combustion in a time step and so the rate of combustion was limited by the amount of $\mathrm{CO}$ or oxygen according to the stoichiometric requirement ('Mixed is burned' model, MIB). In the third way, we directly injected heat through an artificial heat source term in the equation for energy conservation of the gaseous phase. The difference for the temperature outputs between these three modes of the heat source was found existing only near the heat source for any time or at any distance from the heat source, but in a short time from the heat start.

FIRESTAR turbulence model is a $\mathrm{k}-\varepsilon$ model ( $\mathrm{k}$ sets for turbulent kinetic energy and $\varepsilon$ for the dissipation rate of this energy). Different $\mathrm{k}-\varepsilon$ models are implemented in FIRESTAR (standard, RNG, low Reynolds). The predictions of FIRESTAR 2D obtained with the standard and the Nam and Bill sets of parameters were compared with the plume theory predictions. The predictions of FIRESTAR 2D with the two sets of turbulence parameters were close together and beyond some threshold value of height, they showed the same trend as 
plume theory. The threshold of height increased with power (about 2 and $10 \mathrm{~m}$ respectively for 100 and $1600 \mathrm{~kW} / \mathrm{m}$ ) (Fig. 2). This observation illustrates the fact that plume theory should only apply 'far enough' from the heat source.

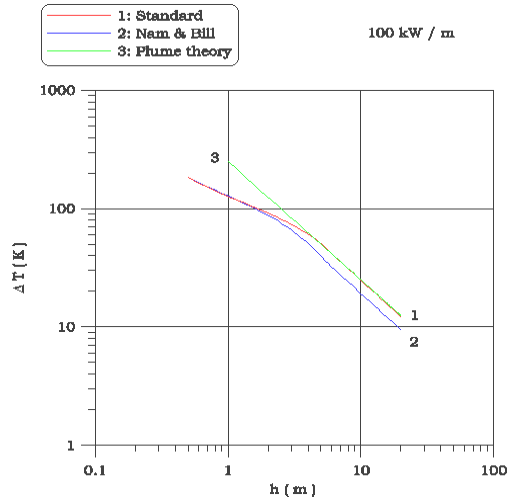

a) Power $100 \mathrm{~kW} / \mathrm{m}$

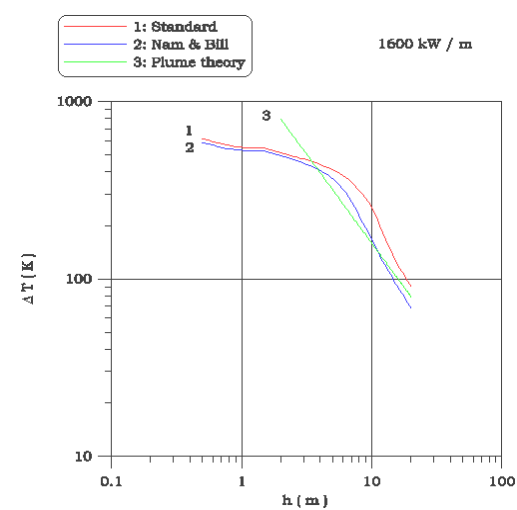

b) Power $1600 \mathrm{~kW} / \mathrm{m}$

Figure 2: Vertical profiles of gas temperature rise as predicted by the FIRESTAR 2D model with two sets of turbulence parameters (standard, Nam and Bill) and by plume theory.

The set of standard parameters gave results closer to plume theory for low powers, the set of Nam and Bill parameters gave results closer to plume theory for high powers.

\section{No-wind simulations (FIRESTAR 2D)}

\subsection{No-canopy simulations}

We first considered the case without any crown and compare the results of FIRESTAR simulations ('virtual crown') with predictions of Van Wagner formula for crown scorch. In both models crown scorch was assumed to occur when gas temperature reached $60^{\circ} \mathrm{C}$. Fig. 3 (a) shows the minimum intensity necessary to get ignition of canopy fuel elements at a given height above the ground. In these 'virtual crown' simulations, we considered that ignition occurred as soon as the gaseous phase reached the ignition temperature of fuel $(600 \mathrm{~K})$. The agreement in crown scorch predictions is excellent.

The predictions of FIRESTAR were fitted to a power law of the fire intensity as shown at Fig. 3 (b) leading to the following formula

$$
h_{i}=18.7 \frac{I^{2 / 3}}{600-T_{a}},
$$

where $T_{a}(\mathrm{~K})$ is the ambient absolute temperature. 


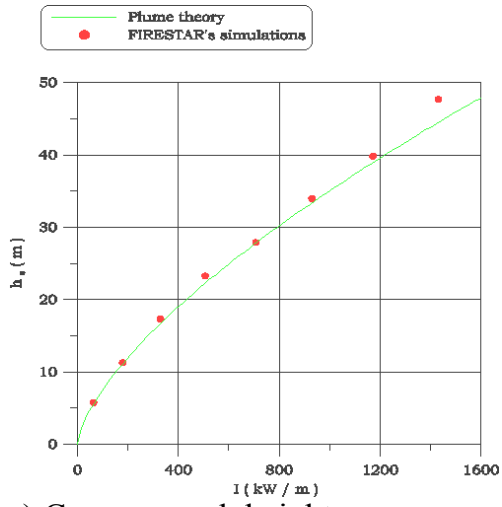

a) Crown scorch heights

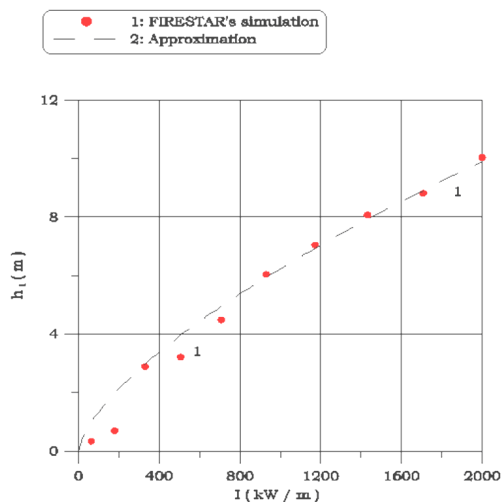

b) Crown fire ignition heights

Figure 3: Crown scorch and crown fire ignition heights as predicted by FIRESTAR 2D in the absence of a tree canopy ('virtual crown').

\subsection{Tree canopy influence}

We defined a tree canopy model based on field measurements of a variety of Aleppo pine (Pinus halepensis) forests in Greece [7]. The maximum density was $0.16 \mathrm{~kg} / \mathrm{m}^{3}$ and the average value was about $0.08 \mathrm{~kg} / \mathrm{m}^{3}$. We added a second family of fuel representing the smallest twigs $(0-6 \mathrm{~mm}$ diameter $)$ with a maximum density half the one of the needles and the same vertical profile. This tree canopy model is called 'light crown' in the following.

We also defined a very dense tree canopy by setting the maximum value of needles density to $0.8 \mathrm{~kg} / \mathrm{m} 3$ (five times denser than the light crown). This second canopy modeled is called 'dense crown' in the following (we ignored twigs in this case). The dense crown can be viewed as a limiting case, not as a realistic canopy.

We used an area-to-volume ratio of $10000 \mathrm{~m}^{-1}$ and a material density of $800 \mathrm{~kg} / \mathrm{m}^{3}$ for needles (data measured on Pinus halepensis, INRA).

As a first step, we considered canopies with crown base height ranging from 3 to $20 \mathrm{~m}$. Based on temperature fields in a large set of simulations, we looked for the minimum intensity that caused scorch at the crown base. The results are plotted on Fig. 4. For a given intensity, we can see that the crown scorch height can be very slightly higher in presence of a canopy than in the no-canopy case ('Virtual crown'). However, this effect was negligible.

Fig. 5 shows scorch heights computed for different pine densities. We also plotted the plume theory prediction and the prediction of FIRESTAR with no crown ('virtual crown') for comparison. Obviously the presence of the canopy increased the crown scorch height with respect to the 'virtual crown' or plume theory predictions. Furthermore, the presence of the canopy had more effect for a dense canopy. 


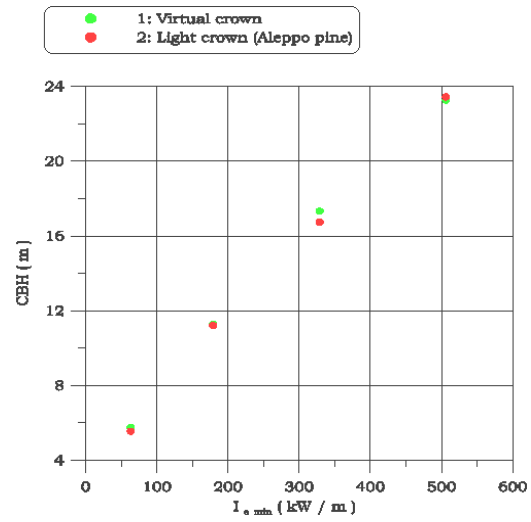

Figure 4: Minimum intensity necessary to get scorch at crown base height level.

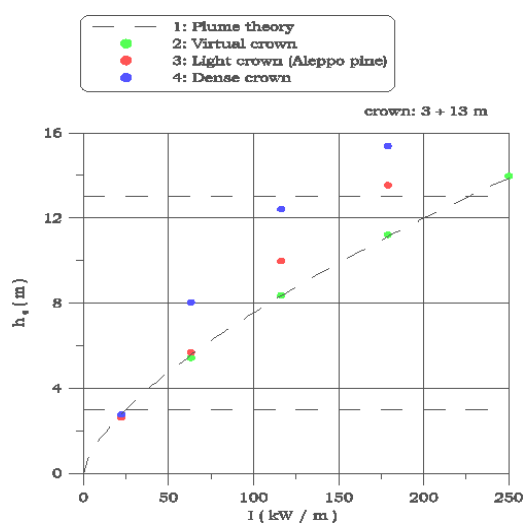

Figure 5: Crown scorch heights as a function of the heat source intensity for crowns ranging between 3 and $13 \mathrm{~m}$.

\section{Wind case results (FIRETEC)}

Here, we considered the effect of a wind on the plume above the heater for the no-canopy and canopy cases, using the FIRETEC code. The domain size was the same as in the preliminary results and the mesh resolution $2 \mathrm{~m} \times 2 \mathrm{~m} \times 2 \mathrm{~m}$ at ground level was used.

In order to represent an infinite plume along the $y$ axis, cyclic boundary conditions on the lateral domain sides were used.

Because the turbulence model of FIRETEC is based on a LES-approach, the most significant part of the turbulence is explicitly solved by the model. In order to obtain mean results, the outputs of FIRETEC were averaged over a significant period of time. 
A vertical wind profile was introduced at the inlet boundary as

$$
U_{x}=U_{0}\left(\frac{z}{H}\right)^{1 / 7},
$$

where the reference height $\mathrm{H}$ is equal to $5 \mathrm{~m}$. The wind speed is defined here with the reference velocity $U_{0}$. We tested two wind velocity levels: $0.1 \mathrm{~m} / \mathrm{s}$, and $1 \mathrm{~m} / \mathrm{s}$; and two power levels: $250 \mathrm{~kW} / \mathrm{m}$, and $1000 \mathrm{~kW} / \mathrm{m}$ (Fig. 6).

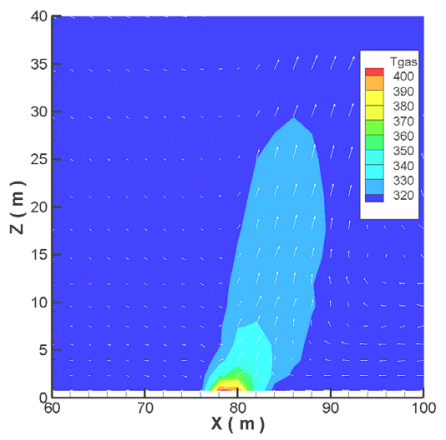

a) Power $250 \mathrm{~kW} / \mathrm{m}$ and wind $0.1 \mathrm{~m} / \mathrm{s}$

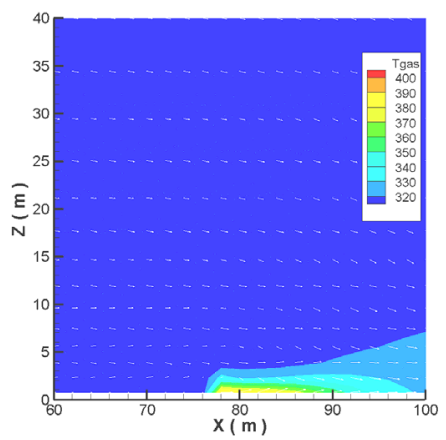

c) Power $250 \mathrm{~kW} / \mathrm{m}$ and wind $1.0 \mathrm{~m} / \mathrm{s}$

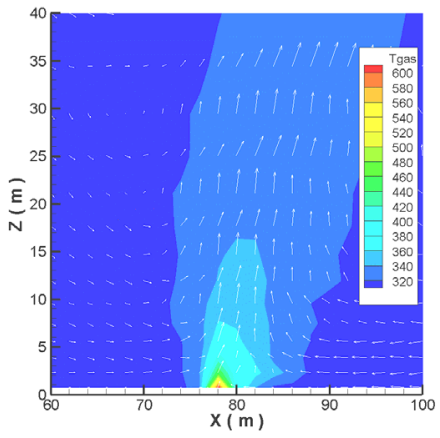

b) Power $1000 \mathrm{~kW} / \mathrm{m}$ and wind $0.1 \mathrm{~m} / \mathrm{s}$

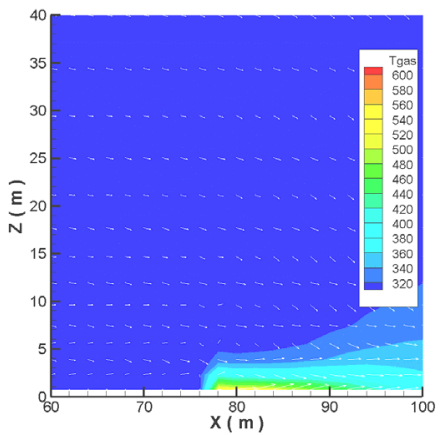

d) Power $1000 \mathrm{~kW} / \mathrm{m}$ and wind $1.0 \mathrm{~m} / \mathrm{s}$

Figure 6: Images of the plume temperature field for two wind velocity levels and two power levels.

One can see significant inclining of the plume with rather weak wind $(1.0 \mathrm{~m} / \mathrm{s})$. We observed a similar effect with FIRESTAR 2D simulator. As expected, the plume is colder when wind speed is higher.

We then tested the effect of the tree canopy presence on the plume. The density was $0.085 \mathrm{~kg} / \mathrm{m}^{3}$. The canopy extended between 3 and $13 \mathrm{~m}$ in both cases. A pre-computation of the wind field using cyclic-conditions at inlet and outlet boundaries of the domain was performed to properly establish the turbulence due to the canopy layer. 


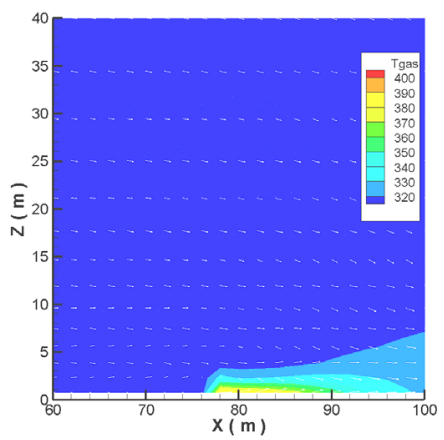

a) No-canopy

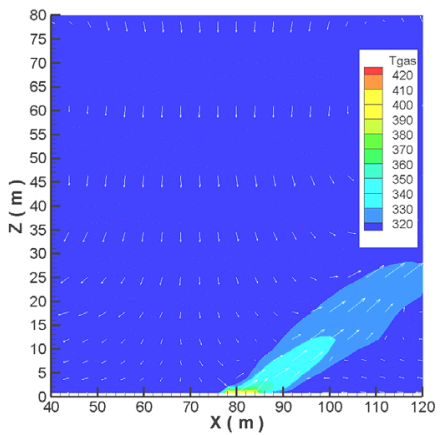

b) Canopy density $0.085 \mathrm{~kg} / \mathrm{m}^{3}$

Figure 7: Images of the plume temperature field for power $250 \mathrm{~kW} / \mathrm{m}$ and wind $1.0 \mathrm{~m} / \mathrm{s}$ for the no-canopy (a) and canopy (b) cases.

Figure 7 illustrates that the canopy existence makes the plume much less inclined. Hence we expect a significant effect of the presence of the canopy layer on the plume and on the temperature distribution, as compared to the predictions of plume theory, which does not consider the canopy effect.

These results are preliminary results with a wind and a canopy and the effect of canopy on the plume should be further investigated before drawing any conclusion.

\section{References}

[1] Thomas, P.H., The size of flames from natural fires. In 'Proceedings of the Ninth International Symposium on Combustion': Academic Press Inc. New York, N.Y., pp. 884-859, 1963.

[2] Thomas, P.H., The effect of wind on plumes from a line heat source. Joint Fire Res. Organ., Fire Res. Stn., Boreham Wood, Engl. Fire Res., Note 572, 1964.

[3] Van Wagner, C.E., Height of crown scorch in forest fires. Canadian Journal of Forest Research, 3(3), pp. 373-378, 1973.

[4] Michaletz, S.T. \& Johnson, E.A., A heat transfer model of crown scorch in forest fires. Canadian Journal of Forest Research, 36:2839-2851, 2006.

[5] Morvan D., Dupuy J.L. (2004) Modeling the propagation of a wildfire through a Mediterranean shrub using a multiphase formulation. Combustion and Flame 138,199-210.

[6] Linn R.R., P. Cunningham (2005), Numerical simulations of grass fires using a coupled atmosphere-fire model: basic fire behavior and dependence on wind speed. Journal of Geophysical Research, 110, D13107.

[7] Mitsoploulos, I.D. \& Dimitrakopoulos, A.P, Canopy fuel characteristics and potential crown fire behaviour in Aleppo pine (Pinus halepensis Mill.) forests. Annals of Forest Science, 64, pp. 287-299, 2007. 